\title{
THE EFFECT OF PREMOLAR EXTRACTIONS ON TOOTH SIZE DISCREPANCIES IN DIFFERENT MALOCCLUSION GROUPS OF EGYPTIAN SAMPLE
}

\author{
Mohammed M Ellaithy* and Nahla E Gomaa*
}

\begin{abstract}
Introduction: In orthodontic treatment, tooth extraction is common to achieve the most acceptable esthetic and functional results for the patients, and the 4 premolars extraction is most common. The Bolton's overall ratio and tooth-size discrepancies are directly affected by premolar extraction. The aim of this study was to investigate the effects of extractions of various combinations of premolars on the Bolton overall ratios and tooth-size discrepancies in different malocclusion groups of a sample of Egyptian orthodontic population.
\end{abstract}

Materials and methods: This study was conducted on study models of 220 patients with varying malocclusions, their age ranged between 15 and 23 years of age, with a mean age of 17.24 years. The subjects were classified into Class I (80 subjects, 25 males and 55 females); Class II ( 88 subjects 26 males and 62 females) and Class III (52 subjects 20 males and 32 females). In each malocclusion group, the Bolton's overall ratios were measured and according to the Bolton overall ratio1 standard deviation $(91.3+1.91 \%)$ subjects were divided into three groups:1) Bolton small (BS) group: small overall ratios (smaller than $89.39 \%, 2$ ), Bolton normal (BN) group: normal overall ratios (between $89.39 \%$ and $93.21 \%, 3$ ), Bolton big (BB) group: big overall ratios (larger than $93.21 \%$ ). In each malocclusion group, hypothetical tooth extractions were performed on each subject in the following 4 combinations: (1) all first premolars, (2) all second premolars, (3) maxillary first and mandibular second premolars, and (4) maxillary second and mandibular first premolars.

Results: The number of small overall ratios was significantly increased after different categories of premolars extraction. The mean values of normal Bolton's over all ratios group was least affected after extractions of all first or maxillary first and mandibular second premolars (the mean differences were -0.13 and 0.01 respectively).

Conclusions: The Bolton overall ratios were significantly decreased after all categories of extraction combination of the premolarsespecially after extraction of all second premolars or maxillary secondand mandibular first premolars. In Patients with normal Bolton overall ratios who need extraction, it is preferred to extract all first or maxillary first and mandibular second premolars to decrease the effect of various premolar extractions on Bolton's overall ratios.

KEY WORDS: Bolton ratio; Tooth size discrepancy; Malocclusion; premolar extraction.

* Lecturer of Orthodontics, Faculty of Dentistry, Tanta University, Egypt. 


\section{INTRODUCTION}

Proper diagnosis and treatment planning are the bases of orthodontic treatment to ensure best possible esthetic and functional results ${ }^{(1)}$.

To achieve proper interdigitation, overbite and overjet, specific dimensional relationships must be present between maxillary and mandibular teeth ${ }^{(2)}$.

A tooth size discrepancy may be defined as disproportion between the sizes of individual teeth and is considered an important variable especially in the anterior segment ${ }^{(3)}$.The amount and location of tooth size discrepancy must be determined before starting treatment to decide either to remove or add tooth structure to open or close spaces in the opposite $\operatorname{arch}^{(2)}$.

Balanced and stable occlusion with optimal occlusion and ideal intercuspation, overjet, overbite is often affected by tooth size discrepancies ${ }^{(4)}$. These factors of tooth size discrepancies have even been described and known as the seventh key of occlusion $^{(5-7)}$.

As the size and form of the teeth are genetically determined and growth and final morphology of the dentofacial structures are affected by environmental factors, the cause of tooth size discrepancy is due to interaction between genetic and environmental factors.

Several methods were suggested for measuring tooth size discrepancy, however, Bolton study is considered the best as it studies tooth size disharmony in relation to treatment of malocclusion ${ }^{(1,8)}$.

Occasionally, patient may have spaces between the teeth after removal of orthodontic appliance, an excessive overjet and an increased overbite ${ }^{(9-11)}$. Tooth size discrepancy between the maxillary and mandibular dental arches may be the cause of these deviations from an ideal occlusion. Space for crowded teeth can be created in three ways: either by expansion of the dental arch, lengthening of the dental arch or by extraction of teeth, or any combination of the three ${ }^{(12-17)}$.
In orthodontic treatment, tooth extraction is often necessary to achieve the best possible esthetic and functional outcome for patients, and the extraction of 4 first premolars is most common ${ }^{(18)}$. So the overall ratio and tooth-size discrepancies are directly affected by premolar extraction.

It was found that the overall ratios after extraction of all premolar combinations were smaller than those before extraction, and, in some of the patients, normal and large overall ratios changed into small and normal overall ratios, respectively, after extraction of premolars ${ }^{(8,19-21)}$. However, other investigators found that the Bolton over all ratios was changed in different ways in different extraction combinations of premolars ${ }^{(22,23)}$. Therefore, the purpose of this study was to investigate the effects of extractions of various combinations of premolars on the Bolton overall ratios and tooth-size discrepancies in different malocclusion groups of a sample of Egyptian orthodontic population.

\section{MATERIAL AND METHODS}

This study was conducted on study models of 220 patients (71 males and 149 females) with varying malocclusions. Pre orthodontic records for patients with varying malocclusion were collected from the Orthodontics Department, Faculty of Dentistry at Tanta University and private orthodontic clinics. A power analysis was conducted to determine the minimum sample size (Statistical power with C.I 95\%: 69.9\%).

The study was performed after receiving the approval of the ethical committee of Faculty of Dentistry, Tanta University.

The age of the subjects was between 15 and 23 years of age, with a mean age of 17.24 years. The selection criteria were: (1) Fully erupted permanent dentition except third molar. (2) Absence of interproximal caries or gross restorations that affect the mesiodistal diameter of the tooth. (3) Good quality study models. (4) Absence of supernumerary teeth and tooth deformity. (5) No tooth agenesis or extraction. 
TABLE (1) Cronbach's alpha of reliability testing.

\begin{tabular}{|c|c|c|c|c|}
\hline $\begin{array}{c}\text { Scale Mean if Item } \\
\text { Deleted }\end{array}$ & $\begin{array}{c}\text { Scale Variance if Item } \\
\text { Deleted }\end{array}$ & $\begin{array}{c}\text { Corrected Item-Total } \\
\text { Correlation }\end{array}$ & $\begin{array}{c}\text { Squared Multiple } \\
\text { Correlation }\end{array}$ & Cronbach's Alpha \\
\hline 90.9123 & 5.443 & .994 & .987 & 0.977 \\
\hline 90.8782 & 5.740 & .994 & .987 & \\
\hline
\end{tabular}

The occlusal characteristics of all subjects were classified using Angle's classification and this coincided with the skeletal relationships. The skeletal relationships were made cephalometrically according to ANB angles on the basis of Aboul Azm et al; $1984^{(24)}$. The subjects were classified into Class I (80 subjects, 25 males and 55 females); Class II (88 subjects 26 males and 62 females) and Class III (52 subjects 20 males and 32 females).

Measurements on the casts were made using digital caliper to the nearest $0.01 \mathrm{~mm}$. Measurements of individual mesiodistal tooth widths were taken from first molar to first molar in each arch. In a well aligned dentition measurements were made from mesial contact point to distal contact point. If teeth were rotated their mesial and distal points in the derotated positions were measured.

Bolton1 overall (first molar to first molar) ratio was calculated with the following formula.

Sum mandibular $12 /$ sum maxillary $12 \times 100=$ overall ratio $(\%)$

Reliability of measurement was determined by randomly selecting and re-measuring 40 dental casts one week after initial measurements. There was no significant difference between the initial and the second set of measurements using Cronbach's alpha of reliability testing (Table 1).

According to the Bolton overall ratio1 standard deviation $(91.3+1.91 \%)$ subjects were divided into three groups:

1) Bolton small (BS) group: small overall ratios (smaller than $89.39 \%$, 2), Bolton normal (BN) group: normal overall ratios (between $89.39 \%$ and
93.21\%, 3) and Bolton big (BB) group: big overall ratios (larger than 93.21\%).

In each malocclusion group, hypothetical tooth extractions were performed on each subject in the following 4 combinations: (1) all first premolars,

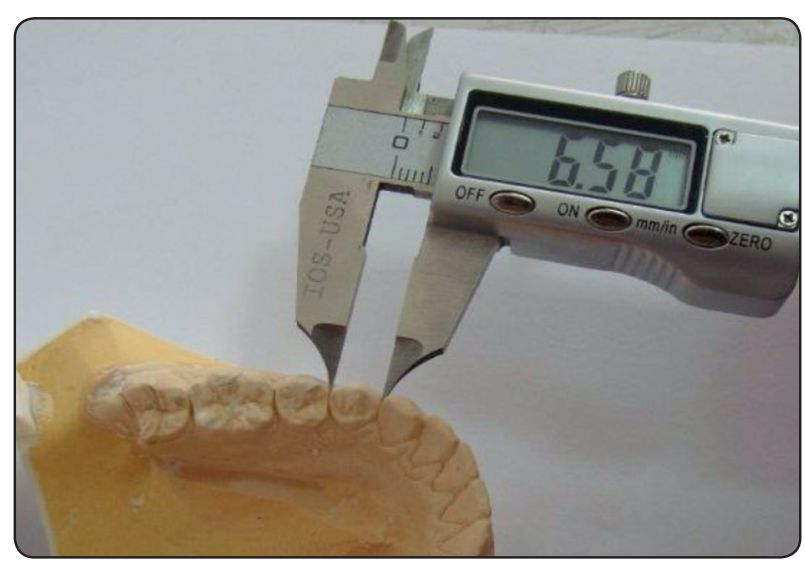

Fig. (1) Mesiodistal width measurement of posterior teeth.

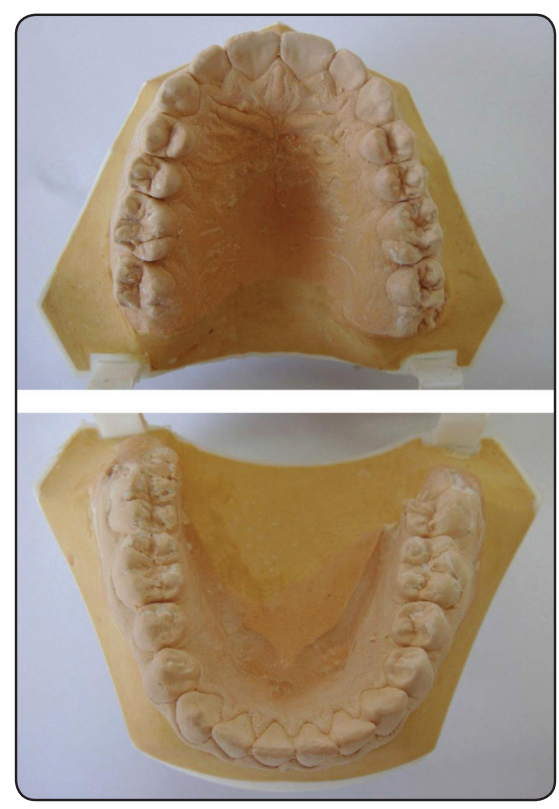

Fig (2) Occlusal views of typical casts used in this study. 
(2) all second premolars, (3) maxillary first and mandibular second premolars, and (4) maxillary second and mandibular first premolars.

The overall ratios were again calculated after the hypothetical extractions in each malocclusion group and compared to see whether and how they were changed for every extraction combination before and after extractions. Similarly, to determine the effect of premolar extraction on overall ratios in different types of malocclusion.

Statistical analyses were performed with SPSS (statistical package for social sciences) version 23.

\section{RESULTS}

The Bolton overall ratios were significantly decreased after all categories of extraction combination of the premolars Table 2, and in all types of malocclusion Table 3 .

Table 4 shows the distribution of the number of different overall ratios before and after extractions. The number of small overall ratios was significantly increased after different categories of extraction combination of the premolars, especially in the extraction combinations of maxillary first and mandibular second premolars, or maxillary second and mandibular first premolars. On the other side, the number of big overall ratios was significantly decreased.

Table 5 the Proportion test indicated that in class I malocclusion, although the number of small and normal overall ratios has a significant difference before and after all categories of extraction combinations, big overall ratios have no significant difference.

On the other hand, in class II and class III malocclusions the number of small and big overall ratios has a significant difference before and after all categories of extraction (with the exception of $4 / 4$ extraction combination in small overall ratios in

TABLE (2) Mean and SD for Bolton overall ratios before and after all categories of extraction combinations of the premolars.

\begin{tabular}{|c|c|c|c|c|}
\hline \multirow{2}{*}{\multicolumn{2}{|c|}{ Before extraction }} & Mean \pm S.D & $\begin{array}{c}\mathrm{p} \text {-value } \\
\text { Significance difference }\end{array}$ & Multiple comparison \\
\hline & & $91.68 \pm 2.11$ & \multirow{5}{*}{$0.000 * *$} & \multirow{2}{*}{$\begin{array}{c}\text { Before extraction } \\
\text { Vs.4/4,5/5,4/5,5/4 }\end{array}$} \\
\hline \multirow{4}{*}{ After extraction } & $4 / 4$ & $90.52 \pm 2.58$ & & \\
\hline & $5 / 5$ & $90.54 \pm 2.48$ & & \multirow[t]{2}{*}{$4 / 4$ Vs.4/5,5/4 } \\
\hline & $4 / 5$ & $89.80 \pm 2.30$ & & \\
\hline & $5 / 4$ & $89.78 \pm 2.46$ & & $5 / 5$ Vs. $4 / 5,5 / 4$ \\
\hline
\end{tabular}

Table (3) One-way ANOVA test comparing Bolton's over all ratios before and after extraction in each malocclusion type.

\begin{tabular}{|c|c|c|c|c|c|c|}
\hline \multirow{2}{*}{ Group } & \multirow{2}{*}{$\begin{array}{c}\text { Before } \\
\text { extraction }\end{array}$} & \multicolumn{4}{|c|}{ After extraction } & \multirow{2}{*}{ p-value } \\
\hline & & $4 / 4$ & $5 / 5$ & $4 / 5$ & $5 / 4$ & \\
\hline Class I & $91.77 \pm 2.01^{\mathrm{a}}$ & $90.53 \pm 2.48^{b}$ & $89.92 \pm 2.26^{\mathrm{bc}}$ & $90.90 \pm 2.47^{\text {abcd }}$ & $89.55 \pm 2.29^{\mathrm{bc}}$ & $0.000 * *$ \\
\hline Class II & $92.07 \pm 2.32^{\mathrm{a}}$ & $90.48 \pm 2.68^{b}$ & $89.87 \pm 2.45^{\text {bc }}$ & $90.61 \pm 2.68^{\text {bcd }}$ & $89.74 \pm 2.45^{\text {bcd }}$ & $0.000 * *$ \\
\hline Class III & $91.75 \pm 1.87^{\mathrm{a}}$ & $90.33 \pm 1.67^{\mathbf{b}}$ & $89.31 \pm 1.96^{\mathbf{b c}}$ & $90.36 \pm 1.89^{\mathrm{bcd}}$ & $89.28 \pm 1.75^{\text {bcd }}$ & $0.000 * *$ \\
\hline
\end{tabular}


TABLE (4) Distribution of the number of different overall ratios before and after extractions.

\begin{tabular}{|c|c|c|c|c|c|c|c|c|c|c|c|}
\hline \multirow{3}{*}{ Category } & \multicolumn{2}{|c|}{$\begin{array}{c}\text { Before } \\
\text { extraction }\end{array}$} & \multicolumn{8}{|c|}{ After extraction } & \multirow{3}{*}{$\begin{array}{c}\text { Proportion test } \\
\begin{array}{c}\text { Significance } \\
\text { difference }\end{array}\end{array}$} \\
\hline & \multirow{2}{*}{$\mathrm{N}$} & \multirow{2}{*}{$\%$} & \multicolumn{2}{|c|}{$4 / 4$} & \multicolumn{2}{|c|}{$5 / 5$} & \multicolumn{2}{|c|}{$4 / 5$} & \multicolumn{2}{|c|}{$5 / 4$} & \\
\hline & & & $\mathrm{N}$ & $\%$ & $\mathrm{~N}$ & $\%$ & $\mathrm{~N}$ & $\%$ & $\mathrm{~N}$ & $\%$ & \\
\hline \multirow{3}{*}{ Small } & \multirow{3}{*}{28} & \multirow{3}{*}{$12.72 \%$} & \multirow{3}{*}{64} & \multirow{3}{*}{$29.09 \%$} & \multirow{3}{*}{72} & \multirow{3}{*}{$32.72 \%$} & \multirow{3}{*}{94} & \multirow{3}{*}{$42.72 \%$} & \multirow{3}{*}{96} & \multirow{3}{*}{$43.63 \%$} & $\begin{array}{r}\text { Before extraction } \\
\text { Vs. } 4 / 4,5 / 5,4 / 5,5 / 4 \\
\end{array}$ \\
\hline & & & & & & & & & & & 4/4vs.4/5,5/4 \\
\hline & & & & & & & & & & & $5 / 5$ vs. $4 / 5,5 / 4$ \\
\hline \multirow[t]{2}{*}{ Normal } & \multirow[t]{2}{*}{143} & \multirow{2}{*}{$65 \%$} & \multirow{2}{*}{136} & \multirow{2}{*}{$61.81 \%$} & \multirow[t]{2}{*}{126} & \multirow{2}{*}{$57.27 \%$} & \multirow[t]{2}{*}{115} & \multirow{2}{*}{$52.27 \%$} & \multirow{2}{*}{111} & \multirow{2}{*}{$50.45 \%$} & $\begin{array}{c}\text { Before extraction } \\
\text { Vs. } 4 / 5,5 / 4\end{array}$ \\
\hline & & & & & & & & & & & 4/4vs.4/5,5/4 \\
\hline Big & 49 & $22.27 \%$ & 20 & $9.09 \%$ & 22 & $10 \%$ & 11 & $5 \%$ & 13 & $5.9 \%$ & $\begin{array}{c}\text { Before extraction } \\
\text { Vs. } 4 / 4,5 / 5,4 / 5,5 / 4\end{array}$ \\
\hline
\end{tabular}

TABLE (5) Distribution of the number of different overall ratios in different malocclusion types before and after extractions.

\begin{tabular}{|c|c|c|c|c|c|c|c|c|c|c|c|}
\hline \multirow{3}{*}{ Class I } & \multicolumn{2}{|c|}{$\begin{array}{c}\text { Before } \\
\text { extraction }\end{array}$} & \multicolumn{8}{|c|}{ After extraction } & \multirow{3}{*}{$\begin{array}{c}\text { Proportion test } \\
\text { Significance } \\
\text { difference }\end{array}$} \\
\hline & \multirow{2}{*}{$\mathbf{N}$} & \multirow{2}{*}{$\%$} & \multicolumn{2}{|c|}{$4 / 4$} & \multicolumn{2}{|c|}{$5 / 5$} & \multicolumn{2}{|c|}{$4 / 5$} & \multicolumn{2}{|c|}{$5 / 4$} & \\
\hline & & & $\mathbf{N}$ & $\%$ & $\mathbf{N}$ & $\%$ & $\mathbf{N}$ & $\%$ & $\mathbf{N}$ & $\%$ & \\
\hline Small & 12 & $15.00 \%$ & 26 & $32.50 \%$ & 26 & $32.50 \%$ & 35 & $43.75 \%$ & 34 & $42.50 \%$ & $\begin{array}{c}\text { Before extraction } \\
\text { Vs. } 4 / 4,5 / 5,4 / 5,5 / 4\end{array}$ \\
\hline Normal & 60 & $75.00 \%$ & 45 & $56.25 \%$ & 45 & $56.25 \%$ & 39 & $48.75 \%$ & 39 & $48.75 \%$ & $\begin{array}{c}\text { Before extraction } \\
\text { Vs. 4/4, 5/5, 4/5, 5/4 }\end{array}$ \\
\hline Big & 8 & $10.00 \%$ & 9 & $11.25 \%$ & 9 & $11.25 \%$ & 6 & $7.50 \%$ & 7 & $8.75 \%$ & ------- \\
\hline Total & 80 & $100 \%$ & 80 & $100 \%$ & 80 & $100 \%$ & 80 & $100 \%$ & 80 & $100 \%$ & ------- \\
\hline \multicolumn{12}{|c|}{ Class II } \\
\hline Small & 10 & $11.36 \%$ & 27 & $30.68 \%$ & 26 & $29.55 \%$ & 36 & $40.91 \%$ & 39 & $44.32 \%$ & $\begin{array}{l}\text { Before extraction } \\
\text { Vs. } 4 / 4,5 / 5,4 / 5,5 / 4\end{array}$ \\
\hline Normal & 50 & $56.82 \%$ & 50 & $56.82 \%$ & 51 & $57.95 \%$ & 47 & $53.41 \%$ & 43 & $48.86 \%$ & -------- \\
\hline Big & 28 & $31.82 \%$ & 11 & $12.50 \%$ & 11 & $12.50 \%$ & 5 & $5.68 \%$ & 6 & $6.82 \%$ & $\begin{array}{l}\text { Before extraction } \\
\text { Vs. } 4 / 4,5 / 5,4 / 5,5 / 4 \\
\end{array}$ \\
\hline Total & 88 & $100 \%$ & 88 & $100 \%$ & 88 & $100 \%$ & 88 & $100 \%$ & 88 & $100 \%$ & ------- \\
\hline \multicolumn{12}{|c|}{ Class III } \\
\hline Small & 6 & $11.54 \%$ & 11 & $21.15 \%$ & 20 & $38.46 \%$ & 23 & $44.23 \%$ & 23 & $44.23 \%$ & $\begin{array}{c}\text { Before extraction } \\
\text { Vs. } 5 / 5,4 / 5,5 / 4\end{array}$ \\
\hline Normal & 33 & $63.46 \%$ & 41 & $78.85 \%$ & 30 & $57.69 \%$ & 29 & $55.77 \%$ & 29 & $55.77 \%$ & $4 / 4$ Vs. $5 / 5,4 / 5,5 / 4$ \\
\hline Big & 13 & $25 \%$ & 0 & $0 \%$ & 2 & $3.85 \%$ & 0 & $0 \%$ & 0 & $0 \%$ & $\begin{array}{l}\text { Before extraction } \\
\text { Vs. } 4 / 4,5 / 5,4 / 5,5 / 4\end{array}$ \\
\hline Total & 52 & $100 \%$ & 52 & $100 \%$ & 52 & $100 \%$ & 52 & $100 \%$ & 52 & $100 \%$ & --.-- \\
\hline
\end{tabular}


class III malocclusion) ; but normal overall ratios have no significant difference before and after extraction.

Table 6 shows that 2-way ANOVA indicated that before extraction there was a significant difference in overall ratios among different malocclusion classes however, there was no significant interaction in malocclusion types between different categories of overall ratios $(\mathrm{P}=0.210)$.

The mean values of normal Bolton's over all ratios group almost not affected after extractions of all first or maxillary first and mandibular second premolars (the mean differences were -0.13 and 0.01 respectively)while, the mean values were decreased after extraction of all second or maxillary second and mandibular first premolars (Table 7).

TABLE (6) Two-way ANOVA of overall ratios before extractions (malocclusion type and extraction category).

\begin{tabular}{|c|c|c|c|c|c|}
\hline Class before & Small & Normal & Big & Malocclusion type & Category \\
\hline extraction & Mean \pm S.D & Mean \pm S.D & Mean \pm S.D & p-value & p-value \\
\hline Class I & $88.56 \pm 0.92$ & $91.62 \pm 1.03$ & $94.46 \pm 0.92$ & \multirow{3}{*}{0.210} & \multirow{3}{*}{$0.000 * *$} \\
\hline Class II & $87.72 \pm 1.27$ & $91.54 \pm 0.96$ & $94.07 \pm 2.26$ & & \\
\hline Class III & $87.95 \pm 1.26$ & $91.74 \pm 0.86$ & $93.67 \pm 0.39$ & & \\
\hline Total & $88.13 \pm 1.14^{\mathrm{a}}$ & $91.61 \pm 0.98^{\mathbf{b}}$ & $94.07 \pm 2.11^{\mathrm{c}}$ & ------- & ------ \\
\hline
\end{tabular}

TABLE (7) One-way ANOVA test comparing Bolton's overall ratios before and after extraction in different categories of overall ratios.

\begin{tabular}{|c|c|c|c|c|c|}
\hline \multirow{2}{*}{\multicolumn{2}{|c|}{ Group }} & Small & Normal & Big & \multirow{2}{*}{ p-value } \\
\hline & & Mean \pm S.D & Mean \pm S.D & Mean \pm S.D & \\
\hline \multicolumn{2}{|c|}{ Before extraction } & $88.13 \pm 1.14$ & $91.13 \pm 6.84$ & $94.05 \pm 1.79$ & \multirow{5}{*}{$0.000 * *$} \\
\hline \multirow{4}{*}{ After extraction } & $4 / 4$ & $87.35 \pm 2.53$ & $91 \pm 1.06$ & $95.34 \pm 1.88$ & \\
\hline & $5 / 5$ & $87.65 \pm 1.70$ & $90.79 \pm 1.01$ & $95.03 \pm 1.78$ & \\
\hline & $4 / 5$ & $87.42 \pm 2.46$ & $91.14 \pm 1.06$ & $95.23 \pm 1.67$ & \\
\hline & $5 / 4$ & $87.49 \pm 2.12$ & $90.79 \pm 0.99$ & $95.19 \pm 1.89$ & \\
\hline \multicolumn{2}{|c|}{ Total } & $87.54 \pm 2.11^{\mathrm{a}}$ & $90.99 \pm 3.49^{b}$ & $94.77 \pm 1.85^{\mathrm{c}}$ & ------ \\
\hline
\end{tabular}




\section{DISCUSSION}

The significance of tooth size discrepancies in orthodontic diagnosis has been widely reported in the literature and accepted by the orthodontic community because the relationship between the upper and lower dentitions is related to orthodontic finishing excellence ${ }^{(25-27)}$.

Mesiodistal tooth size of the maxillary and mandibular arches should be in balance to give proper interdigitation, overbite and overjet at the end of orthodontic treatment.

Several methods have used by orthodontists to detect interarch tooth size discrepancies in patients presenting for orthodontic treatment. The Bolton analysis ${ }^{(1,8)}$, remains the most perceived and widely used method to detect interarch tooth size discrepancies. It can be defined as the ratios between the sums of mesiodistal tooth diameter of the mandibular and the maxillary dentitions.

One of the major diagnostic decisions that are required in orthodontic treatment is whether to extract to properly align the other teeth. So, the present study was to investigate the effects of extractions of various combinations of premolars on the Bolton overall ratios and tooth-size discrepancies in Egyptian orthodontic population.

Two hundred and twenty pretreatment casts of patients with varying malocclusion, their ages ranged from 15 to 25 years old were used in this study. Young age groups were chosen to minimize the alteration of the mesiodistal tooth dimensions because of factors such as attrition, restoration or caries.

Several methods are available for measuring tooth width. It could be performed with the aid of either needle pointed dividers, Boley guage (vernier calipers), digital calipers or computerized methods.

Zilberman et al; $2003^{(28)}$ tested the accuracy of measuring casts and concluded that measurement with digital calipers on plaster models produced the most accurate and reproducible results.

In the present study, the number of cases who have small Bolton's overall ratios was increased after all combinations of premolar extractions. This finding was supported by the finding of Tong et al; 2004 ${ }^{(21)}$ who concluded that the decrease in the overall ratio in any extraction combinations might be because the ratios of the mesiodistal widths of the maxillary first or second premolars to those of the 12 maxillary teeth were smaller than those of the mandibular first or second premolars to the 12 mandibular teeth.

While, the study of Heusdens et al; 2000 (29) indicated that only big pretreatment Bolton's overall ratios were affected, where small ones were not affected, our study showed that all ratios were significantly changed before and after extraction which is in line with Tong et al; 2004 ${ }^{(21)}$ and Varghese et al; $2016^{(30)}$

The results of the present study showed that, the mean of big overall ratio was increased after extraction of all combinations of premolar extractions while, the mean of small ones was decreased. This finding was in agreement with Tong et al; 2004(21) and disagreed with those of Endo et al; 2010 (23) who found that there is no effect of premolar extraction on the number of big Bolton's overall ratios. The increase of the mean of big Bolton's overall ratios in the present study may be due to the shift of many cases from big to normal and small Bolton's overall ratios leaving only cases with the extreme overall ratios which led to increase of the mean Bolton's overall ratios after extraction.

In the present study, the number of the small over all ratios was increased after of all categories of premolar extraction in different malocclusion groups, while the number of big over all ratios was significantly decreased in class II and class III. This may attributed to the tendency towards higher mesiodistal widths of the mandibular teeth in class II $^{(31,32)}$ and class III ${ }^{(4,5,33-35)}$. 
Our findings showed that the mean of overall ratios were mostly affected after extraction of all second premolars or maxillary second and mandibular first premolars, as it decreased by (1.85 and 2.22 in class I and 2.2 and 2.33 in class II respectively). These findings supported by those of Endo et al; $2010^{(23)}$ who demonstrated that, the mean overall ratios in the Class I and Class II malocclusion groups ranged from $87 \%$ to $89 \%$ after extraction of all second premolars or maxillary second and mandibular first premolars. They attributed this decrease in the overall ratio in any extraction combinations to that, the ratios of the mesiodistal widths of the maxillary first or second premolars to those of the 12 maxillary teeth were smaller than those of the mandibular first or second premolars to the 12 mandibular teeth.

However, the number of cases who have small Bolton's overall ratios was increased after all combinations of premolar extractions especially after extraction of maxillary first and mandibular second premolars or maxillary second and mandibular first premolars, the mean values of normal Bolton's over all ratios group almost not affected after extractions of all first or maxillary first and mandibular second premolars (the mean differences were -0.13 and 0.01 respectively). These results were compatible with the finding of Kumar et al; 2013 ${ }^{(36)}$ and Varghese et al; 2016 ${ }^{(30)}$ who advised and preferred extraction of all first or maxillary first and mandibular second premolars in cases with normal Bolton's overall ratios to decrease the effect of various premolar extractions on Bolton's overall ratios.

\section{CONCLUSIONS}

On the basis of the data obtained, the conclusion of the present study can be summarized as follow:

The Bolton overall ratios were significantly decreased in all types of malocclusion after all categories of extraction combination of the premolars especially after extraction of all second premolars or maxillary second and mandibular first premolars.
In patients with normal Bolton overall ratios who need extraction, it is preferred to extract all first or maxillary first and mandibular second premolars to decrease the effect of various premolar extractions on Bolton's overall ratios.

\section{REFERENCES}

1- Bolton WA. Disharmony in tooth size and its relation to the analysis and treatment of malocclusion. Angle Orthod. 1958; 28: 113- 30 .

2- Smith SS, Buschang PH, Watanabe E. Interarch tooth size relationships of 3 populations: Does Bolton's analysis apply? Am J Orthod Dentofacial Orthop. 2000; 117: 168- 74.

3- Proffit WR. Contemporary Orthodontics, $3^{\text {rd }}$ Edition, Mosby, St Louis, p 170 .

4- Araujo E, Souki M. Bolton anterior tooth size discrepancies among different malocclusion groups. Angle Orthod. 2002; 73: 307- 13 .

5- Lavelle CLB. Maxillary and mandibular tooth size in different racial groups and in different occlusal categories. Am J Orthod. 1972; 61: 29- 37.

6- Crosby DR, Alexander CG. The occurrence of tooth size discrepancies among different malocclusion groups. Am J Orthod Dentofacial Orthop. 1989; 95: 457- 61.

7- Mc Laughlin Mc, Bennet JC, Trevisi HJ. Systemized orthodontic treatment mechanics. Mosby, 2001; p 285.

8- Bolton WA. The clinical application of a tooth-size analysis. Am J Orthod. 1962; 48: 504- 29.

9- Bishara SE. Management of diastemas in orthodontics Am J Orthod. 1972; 61: 55- 63.

10- Claridge D. Evaluating tooth size in premolar extraction cases. Am J Orthod. 1973; 64: 457- 68.

11- Van Der Linden FDGM, Boersma H. Diagnosis and treatment planning in dentofacial orthopedics. London: Quintessence publishing Co. Ltd., 1987: 117- 58.

12- Nance HN. The limitations of orthodontic treatment: II, diagnosis and treatment in the permanent dentition. Am J Orthod Oral Surg. 1947; 33: 253- 301.

13- Neff CW. Tailored occlusion with the anterior coefficient. Am J Orthod. 1949; 35: 309- 14.

14- Neff CW. The size relationship between the maxillary and mandibular anterior segments of the dental arch. Angle Orthod. 1957; 27: 138- 47. 
15- Steadman SR. The relation of upper anterior teeth to lower anterior teeth as present on plaster models of a group of acceptable occlusions. Angle Orthod. 1952; 22: 91- 7.

16- Rees DJ. A method for assessing the proportional relation of apical bases and contact diameters of the teeth. Am J Orthod. 1953; 39: 695- 707.

17- Lundström A. Intermaxillary tooth width ratio and tooth alignment and occlusion. Acta Odontol Scand. 1954; 12: $265-92$.

18- Vaden JL, Kiser HE. Straight talk about extraction and nonextraction: a differential diagnostic decision. Am J Orthod Dentofacial Orthop. 1996; 109: 445- 52.

19- Li YC, Zhu ZX, Li M, et al. The effect of premolar extractions on Bolton index. Chin J Orthod. 2001; 8: 59- 61.

20- Yang MZ, Xu TM, Lin JX. Bolton analysis of four first premolar extraction cases with good occlusion [in Chinese]. Chin J Orthod. 2002; 9: 32- 34.

21- Tong H, Chen D, Xu L, Liu P. The effect of premolar extractions on tooth size discrepancies. Angle Orthod. 2004; 74: 508- 11.

22- Saatci P, Yukay F. The effect of premolar extractions on tooth size discrepancy. Am J Orthod DentofacialOrthop. 1997; 111: 428- 34.

23- Endo T, Ishida k, Shundo I, Sakaeda K, Shimooka S. Effects of premolar extractions on Bolton overall ratios and tooth-size discrepancies in a Japanese orthodontic population. Am J Orthod Dentofacial Orthop. 2010; 137: 508- 14.

24- Aboul-Azm, Enany N and Fahmy M. The Alexandria analysis. Radiographic cephalometric standards for Egyptian adults. Alex Dent J. 1984; 9:1-9.

25- Uysal T, Sari Z, Bascifiti FA, Memili B. Intermaxillary tooth size discrepancy and malocclusion: is there a relation? Angle Orthod. 2005;75: 208-13.
26- V. Paulino, V. Paredes, J.L. Gandia. Prediction of arch length based on intercanine width. Eur J Orthod. 2008; 30: 295-98.

27- Othman SA, Harradine NWT. Tooth size discrepancy and Bolton's ratios: a literature review. J Orthod. 2006; 33:45-51.

28- Zilberman O, Huggare JAV, Parikakis KA. Evaluation of the validity of tooth size and arch width measurements using conventional and 3- dimensional virtual orthodontic models. Angle Orthod. 2003; 73: 301-6.

29- Heusdens M, Dermaut L, Verbeeck R. The effect of tooth size discrepancy on occlusion: An experimental study. Am J Orthod Dentofacial Orthop. 2000; 117: 184-91.

30- Varghese S, Yerasi P, Jose L, Haris T, Mathew T, Ealla K. Outcome of premolar extractions on Bolton's overall ratio and tooth size discrepancies in South India. J Int Soc Prev community Dent. 2016; 6(4): 309- 315.

31- Batool I,Abbas A,Rizvi SA,Abbas I.Evaluation of tooth size discrepancy in different malocclusion groups. J Ayub Med Coll Abbottabad 2008;20:51-54.

32- Khan R ,Antony VV .Evaluation of tooth size discrepancies among different malocclusion groups in Sirte -Libya. Journal of Dental and Medical Sciences 2013;6:15-18.

33- Sperry TP, Worms FW, Isaacson RJ, Speidel TM. Tooth size discrepancy in mandibular prognathism. Am J Orthod 1977; 72: 183-90.

34- Nie Q, Lin J. Comparison of intermaxillary tooth size discrepancies among different malocclusion groups. Am J Orthod Dentofacial Orthop 1999; 116: 539-44.

35- Hamid Reza Fattahi, Hamid Reza Pakshir and Zohreh Hedayati. Comparison of tooth size discrepancies among different malocclusion groups. Eur J Orthod. 2006 ;28:491-95

36- Kumar P, Singh V, Kumar P, Sharma P, Sharma R. Effects of premolar extractions on Bolton's overall ratio and tooth size discrepancies in a north India population. J Orthod Sci. 2013; 2 (1): 23-27. 